\title{
Modelling of Cutting Tool Condition Monitoring System (CTCMS) to support industry 4.0
}

\author{
Ari Setiawan ${ }^{1 *}$, Dina Angela ${ }^{2}$ and Billy Irawan $^{2}$ \\ ${ }^{1}$ Industrial Engineering, Institut Teknologi Harapan Bangsa, 40132 Bandung, Indonesia \\ ${ }^{2}$ Information Technology, Institut Teknologi Harapan Bangsa, 40132 Bandung, Indonesia
}

\begin{abstract}
One of the value drivers in Industry 4.0 is asset utilization that has capability to remote monitoring and controlling the assets. Some of the problems on the production floor, especially in modern manufacturing areas such as machining process in the Flexible Manufacturing System (FMS), requires the condition of the cutting tools. This paper will discuss a model of cutting tools online monitoring system that operated in web based application. The model involves three sensors and a human machine interface to show the cutting tools condition. The sensors consist of temperature sensor, accelerometer, and electrical power consumption sensor; while in the experiment, the data of those sensors will be compared with the flank wear and crater wear on the cutting tools. The model shows that the data of temperatures, vibration and power consumption are collected by the sensors and sent by internet to the monitoring systems.
\end{abstract}

\section{Introduction}

The manufacturing enterprises in the Industrial 4.0 exploit the advantage of IoT (the Internet of Things), which related to the information technology to help solve industries problems. Baur et al. [1] stated that there are eight value drivers in Industry 4.0, which are resource/process, asset utilization, labour, inventory, quality, supply/demand match, time to market, service/after sales. Related to asset utilization, Industry 4.0 can provide data for predictive maintenance including remote monitoring and control. Gania et al. [2] explained that one of the solutions for Industry 4.0 is to utilize the facilities of Flexible Manufacturing System (FMS).

The cutting tools are the important tools in the FMS. Setiawan et al. [3] consider the cutting tools lifetime in production scheduling for the FMS. In the real situation, the cutting tools may broke before its lifetime. Therefore Setiawan et al. [4] developed production rescheduling in FMS. The research in Setiawan et al. [3] and [4] are the analytical modelling to get optimal solution. The implementation model requires a system that has capability to monitor the cutting tool condition.

The study of the cutting tools has been initiated by Taylor [5] that the cutting tool conditions are determined by the crater and flank wear. The cutting tool wear rate are exponential and determined the cutting tool lifetime. Chao et al. [6] used an improved

*Corresponding author: ari_setiawan@ithb.ac.id 
neural network model to predict the life of the cutting tools. While Vagnorius et al. [7] explains that cutting tool conditions can be determined with several causes of wear and tear, internal stresses, grinding errors and the cutting tool installation. The reliability model that developed by Vagnorius et al. has been using the Weibull distribution function.

The wear and tear on the cutting tools will increase the cutting force and the energy consumption. Meanwhile the temperature is also increase, as well as the vibration. To monitor the cutting tool condition, Cus et al. [8] developed Adaptive Neuro - Fuzzy Inference System (ANFIS) to process the cutting force data from the dynamometer. While Huo et al. [9] monitor the cutting tool conditions by utilizing acoustic emission (AE) sensors. Kovac et al. [10] predicts the life of the cutting tools by using thermocouple. In the next study, Kovac et al. [11] improved the model by utilizing the dynamometer, acoustic emission (AE) sensor, three component accelerometer and CCD vision systems to monitor the cutting tool conditions

The research proposed in this paper is to develop a model of Cutting Tool Condition Monitoring System (CTCMS) that supports the application of the concept of Industry 4.0. The development of CTMS began with a simple experiment of installing sensors of electrical energy consumption, temperature sensors and vibration sensors on manual (conventional) lathe before being implemented in the FMS. In general, the type of sensor used to capture temperature data is contactless temperature sensor (MLX-90614), while to capture vibration data using LIS-3DH accelerometer sensor. The electric energy consumption is measured by IC-ADE7758. The obtained data are transmitted over the internet to the database to be extracted to the cutting tools condition data. This paper also explains the type of data will be obtained from the sensor and how they are processed into the information condition of cutting tool. The data that has been processed can be seen by the production supervisor of the office by utilizing web facilities.

\section{Cutting Tool Monitoring Hardware Configuration}

Configuration of the sensor on the lathe is shown in Figure 1. The location of the temperature sensor and vibration sensor is located on a removable shank tool holder with its cutting tool. The tool holder is then mounted on the post tool on the lathe. While the electrical consumption sensor installed serially with a power source with the electrical motor on the lathe. These three types of sensors are connected to a microcomputer that can transmit data over the internet 


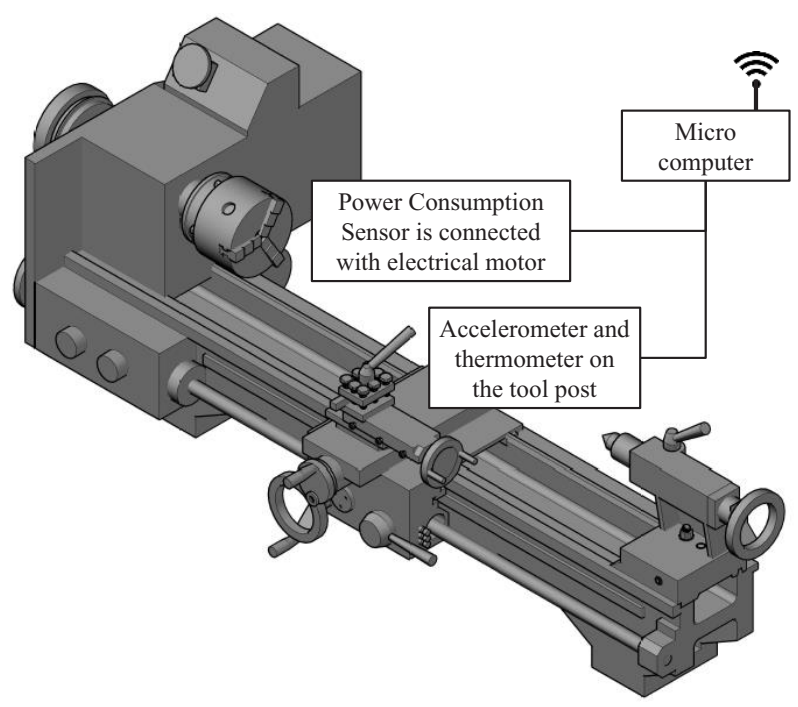

Fig. 1. The configuration of sensors on conventional lathe.

The measurement for both crater wear and flank wear is still done manually, i.e. by using a magnifying glass and compared with a linear measuring instrument with the accuracy of $0.01 \mathrm{~mm}$. This wear measurement model is still in the refinement stage to increase the better accuracy up to $0.005 \mathrm{~mm}$.

\section{Model Development}

The Cutting Tool Condition Monitoring System model begins by observing the wear principle on the chisel, which reduces the cutting tools lifetime. As the cutting tools begin to be used, the crater wear and flank wear begin to occur. If a worn cutting tool is used for cutting, it will cause an increase in temperature and vibration on the cutting tools as well as increasing power consumption. In this research, it has not considered the machining process parameters, such as cutting speed, cutting feed and depth of cut for various types of the workpiece materials and the geometry and cutting tool materials.

\subsection{Mathematical Model Formulation}

The cutting tool condition model is presented with the reliability function of the cutting tool, which is denoted as follows:

$R(t)=$ cutting tools reliability function at time $t$.

$T(t)=$ temperature at time $t$.

$X(t)=$ vibration at time $t$.

$P(t)=$ power consumption at time $t$.

$\beta=$ shape parameter in the Weibull distribution.

$\theta=$ scale parameter in the Weibull distribution

$M T T F=$ mean time to failure of cutting tools

$U=$ cutting tool life time

$V_{c}=$ cutting speed 
$W_{f}=$ flank wear on cutting tools

$W_{c}=$ create wear on cutting tools

$$
R(t)=f(T(t), X(t), P(t))
$$

While the reliability function is related to the Weibull distribution, which is related to the shape and scale parameter [7].

$$
\begin{gathered}
R(t)=e^{-\left(\frac{t}{\theta}\right)^{\beta}} \\
M T T F=U=\theta \cdot \Gamma\left(1+\frac{1}{\beta}\right)
\end{gathered}
$$

Taylor [5] formulated the cutting tools life time $(U)$ :

$$
v_{c} \cdot U^{n}=C
$$

While, the reliability on cutting tool is related with flank and crater wear:

$$
R(t)=f\left(W_{f}, W_{c}\right)
$$

The concept of this research is to prepare the modelling of relation of the temperature, the vibration and the power consumption to the cutting tools life time, considering the wear on cutting the tools.

\subsection{Object-Oriented Modelling Approach}

The web application of Cutting Tool Condition Monitoring System is developed following the object-oriented modelling approach. There are seven classes in the Unified Modelling Language (UML) diagram which are machine tool class, power sensor class, accelerometer class (for the vibration sensor), cutting tool class, raw material class and the CTCMS class. Each classes have attributes that related to the CTCMS class as shown in the Figure 2. 


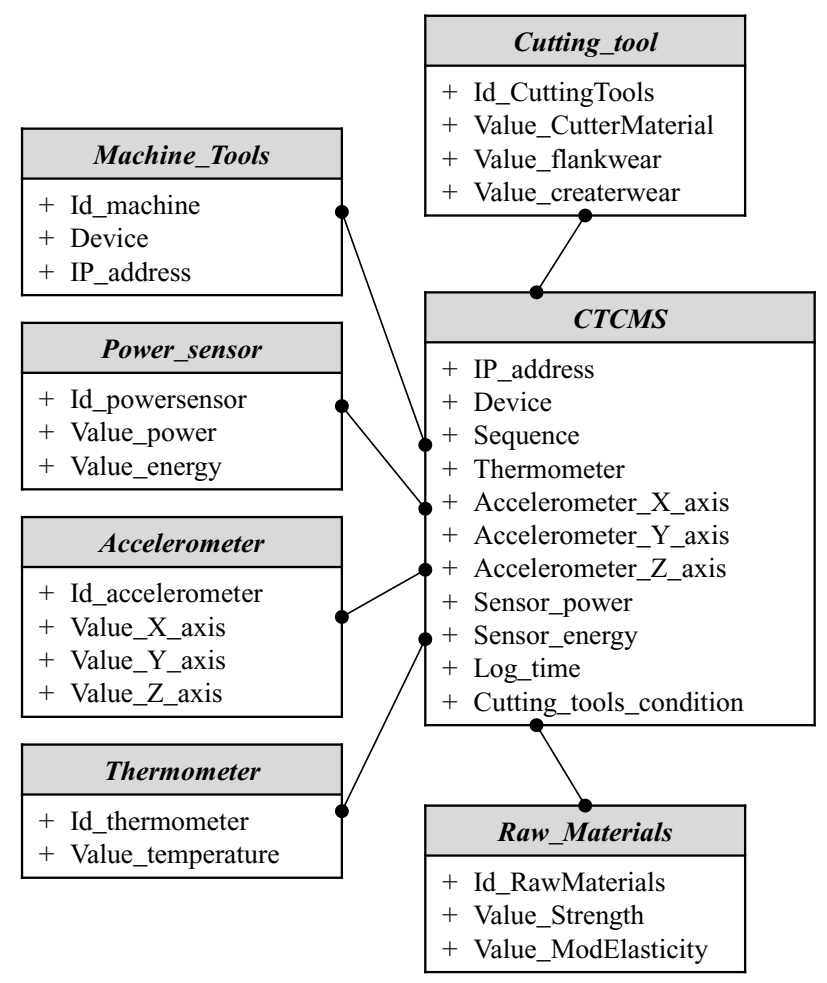

Fig. 2. The UML and Class diagram.

There are five stages to complete the CTCMS hardware and the web application. The stage one is to test the prototype of CTCMS hardware and the web application. The objective in this stage is to transmit and present the data. The stage two is the algorithm development to build the relation of the temperature, vibration, power consumption data and the wear on the cutting tools. The stage three is building the database of the combination various raw materials and the cutting tools geometry and materials. The stage four is to enrich the database of the variation of the cutting parameters, which are cutting speed, feed and depth of cut. The stage five is refinement the CTCMS hardware and web application. As this paper is prepared, the research is in the stage one.

\section{Exercise and Analysis of Stage One}

The prototype of the CTCMS has been developed and tested on several exercises. The objective of the exercises is test the hardware capabilities to send and store the data in the database. Nevertheless, the data for the exercises are as follows:

The cutting tool material is HSS with straight geometry as shown in Figure.3. The raw material is wood (non-metallic materials), rod shape which has $80 \mathrm{~mm}$ in diameter and $400 \mathrm{~mm}$ long. The cutting speed is $75 \mathrm{~m} / \mathrm{min}$, feed $25 \mathrm{~mm} / \mathrm{min}$ and $3 \mathrm{~mm}$ depth of cut. Since the wear on cutting tool is measured manually and limited accuracy, the wear rate is assumed constant and the maximum crater or flank wear is $0.01 \mathrm{~mm}$. The result of data acquisition from sensors is presented in Table.1. The units for wear is in $\mathrm{mm}$, temperature in Celsius, vibration in $\mathrm{mm}^{2}$ /second, and power in watt. 


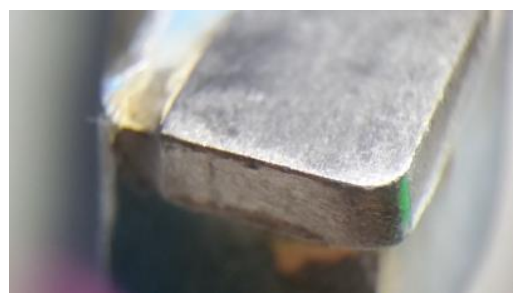

Fig. 3. The HSS Cutting tool.

Table 1. The data of wear, vibrations, power consumption and login time.

\begin{tabular}{|c|c|c|c|c|c|c|c|}
\hline \multirow{2}{*}{ No. } & \multirow{2}{*}{ Wear } & \multirow{2}{*}{ Temp } & \multicolumn{3}{|c|}{ Vibration } & Pow- & $\begin{array}{c}\text { Log } \\
\text { time }\end{array}$ \\
\cline { 4 - 6 } & & & $\mathbf{X}$ & $\mathbf{Y}$ & $\mathbf{Z}$ & $\mathbf{2}$ & $\mathbf{2}$ \\
\hline 1 & 0.002 & 26.99 & 0.08 & 9.22 & 0.23 & 2040 & $53: 39$ \\
\hline 2 & 0.004 & 26.99 & 0.06 & 9.25 & 0.34 & 2040 & $53: 46$ \\
\hline 3 & 0.006 & 26.97 & 0.04 & 9.22 & 0.31 & 2040 & $53: 52$ \\
\hline 4 & 0.008 & 26.97 & -0.06 & 9.22 & 0.25 & 2040 & $53: 55$ \\
\hline 5 & 0.010 & 26.97 & 0.1 & 9.29 & 0.21 & 2040 & $54: 00$ \\
\hline 6 & 0.012 & 26.97 & 0.02 & 9.25 & 0.54 & 2040 & $54: 05$ \\
\hline 7 & 0.013 & 26.99 & -0.04 & 9.29 & 0.25 & 2040 & $54: 10$ \\
\hline 8 & 0.015 & 26.99 & 0.06 & 9.27 & 0.25 & 2040 & $54: 22$ \\
\hline 9 & 0.017 & 26.99 & -0.04 & 9.22 & 0.34 & 2040 & $54: 27$ \\
\hline 10 & 0.019 & 27.03 & 0.04 & 9.06 & 0.4 & 2041 & $54: 32$ \\
\hline 11 & 0.021 & 26.99 & 0.02 & 9.29 & 0.36 & 2042 & $54: 36$ \\
\hline 12 & 0.023 & 26.99 & 0 & 9.22 & 0.54 & 2042 & $54: 40$ \\
\hline 13 & 0.025 & 27.03 & 3.03 & 7.38 & 8.99 & 2042 & $54: 44$ \\
\hline 14 & 0.027 & 29.63 & -3.33 & 3.43 & -6 & 2043 & $54: 51$ \\
\hline 15 & 0.029 & 30.05 & 4.41 & 10.13 & 3.56 & 2043 & $54: 56$ \\
\hline 16 & 0.031 & 31.43 & 1.26 & 11.13 & 1.28 & 2044 & $55: 00$ \\
\hline 17 & 0.033 & 35.63 & -5.8 & 13.12 & 1.36 & 2045 & $55: 05$ \\
\hline 18 & 0.035 & 37.29 & -14.02 & 16.11 & 1.34 & 2045 & $55: 10$ \\
\hline 19 & 0.037 & 40.55 & -8.89 & 16.02 & 6.65 & 2046 & $55: 14$ \\
\hline 20 & 0.038 & 42.25 & 1.82 & 10.13 & -3.01 & 2046 & $55: 19$ \\
\hline 21 & 0.040 & 44.41 & -0.33 & 12.53 & -1.8 & 2047 & $55: 25$ \\
\hline 22 & 0.042 & 44.01 & -0.75 & 7.41 & -1.57 & 2047 & $55: 29$ \\
\hline 23 & 0.044 & 44.03 & -1.23 & 9.79 & 1.03 & 2048 & $55: 34$ \\
\hline 24 & 0.046 & 43.43 & -7.45 & 11.69 & 3.97 & 2048 & $55: 38$ \\
\hline 25 & 0.048 & 41.93 & -0.9 & 6.09 & -0.8 & 2049 & $55: 43$ \\
\hline 26 & 0.050 & 40.61 & -0.9 & 8.51 & -0.5 & 2049 & $55: 48$ \\
\hline 27 & 0.052 & 40.85 & 4.48 & 16.15 & -3.45 & 2050 & $55: 52$ \\
\hline 28 & 0.054 & 39.89 & 1.78 & 9.2 & -2.72 & 2050 & $55: 56$ \\
\hline 29 & 0.056 & 38.85 & 0.5 & 7.74 & -0.38 & 2051 & $56: 00$ \\
\hline 30 & 0.058 & 38.71 & -10.94 & 6.51 & -2.76 & 2051 & $56: 04$ \\
\hline 31 & 0.060 & 38.59 & -0.4 & 12.3 & 3.47 & 2052 & $56: 10$ \\
\hline 32 & 0.062 & 38.89 & 1.32 & 9.2 & 1.88 & 2052 & $56: 16$ \\
\hline 33 & 0.063 & 38.49 & -2.36 & 2.61 & -0.02 & 2052 & $56: 22$ \\
\hline 34 & 0.065 & 38.75 & -1.71 & 8.24 & -0.15 & 2053 & $56: 27$ \\
\hline 35 & 0.067 & 38.59 & 0.15 & 10.94 & 9.29 & 2054 & $56: 33$ \\
\hline 36 & 0.069 & 37.45 & 0.13 & 9.25 & 0.34 & 2054 & $56: 40$ \\
\hline 37 & 0.071 & 36.81 & 0.06 & 9.2 & 0.27 & 2054 & $56: 45$ \\
\hline 38 & 0.073 & 36.39 & 0.06 & 9.2 & 0.04 & 2054 & $56: 50$ \\
\hline 39 & 0.075 & 35.99 & 0.08 & 9.29 & 0.25 & 2054 & $56: 53$ \\
\hline
\end{tabular}




\begin{tabular}{|l|c|c|c|c|c|c|c|}
\hline 40 & 0.077 & 35.45 & 0.11 & 9.22 & 0.15 & 2054 & $56: 59$ \\
\hline 41 & 0.079 & 35.21 & 0.11 & 9.23 & 0.25 & 2054 & $57: 03$ \\
\hline 42 & 0.081 & 34.93 & 0.02 & 9.22 & 0.33 & 2054 & $57: 07$ \\
\hline 43 & 0.083 & 34.67 & 0.11 & 9.29 & 0.23 & 2054 & $57: 11$ \\
\hline 44 & 0.085 & 34.39 & 0.08 & 9.27 & 0.29 & 2054 & $57: 14$ \\
\hline 45 & 0.087 & 34.15 & -0.06 & 9.2 & 0.25 & 2054 & $57: 19$ \\
\hline 46 & 0.088 & 33.95 & 0.11 & 9.22 & 0.27 & 2054 & $57: 23$ \\
\hline 47 & 0.090 & 33.79 & 0.04 & 9.22 & 0.27 & 2054 & $57: 27$ \\
\hline 48 & 0.092 & 33.63 & 0.21 & 9.27 & -0.21 & 2054 & $57: 30$ \\
\hline 49 & 0.094 & 33.47 & 0.08 & 9.25 & 0 & 2054 & $57: 35$ \\
\hline 50 & 0.096 & 33.35 & 0.1 & 9.31 & 0.27 & 2054 & $57: 39$ \\
\hline 51 & 0.098 & 33.25 & 0.06 & 9.18 & 0.21 & 2054 & $57: 42$ \\
\hline 52 & 0.100 & 33.13 & 0.04 & 9.2 & 0.27 & 2054 & $57: 47$ \\
\hline
\end{tabular}

The data is then processed to obtain the relationship between the relationship of the cutting tool reliability function to the temperature, vibration and consumption data, as compiled in formula (1). Table 2 shows the regression statistics of the data to develop the multiple linear regression equation in 52 observations. Correlation coefficient (Multiple R) 0,976 indicates strong linear association between dependent variable (wear) and independent variables (temperature, vibration, and power data). Coefficient determination ( $\mathrm{R}$ square) indicates $95,26 \%$ of total variation of wear explained by the independent variables.

Table 2. The regression statistics.

\begin{tabular}{lr}
\hline \multicolumn{2}{c}{ Regression Statistics } \\
\hline Multiple R & 0,9760 \\
R Square & 0,9526 \\
Observations & 52 \\
\hline
\end{tabular}

Table 3 show result of the analysis of variance (ANOVA). The total sum of square $(0,0412$ $+0,002=0,0433)$ is the squared error that would occur. Using the values of independent variables reduces this error by $95,15 \%$ or $(0,0412 / 0,0433)$. This reduction is deemed statistically significant with an $F$ ratio of 185,15 and a significance level of 0,00 .

Table 3. The analysis of variance.

\begin{tabular}{lrrrr}
\hline & $\boldsymbol{d} \boldsymbol{f}$ & $\boldsymbol{S S}$ & $\boldsymbol{F}$ & Sig. $\boldsymbol{F}$ \\
\hline Reg. & 5 & 0,0412 & 185,15 & 0,00 \\
Residu. & 46 & 0,0020 & & \\
Total & 51 & 0,0433 & & \\
\hline
\end{tabular}

Table 4 is the coefficients for multiple linear regression. The value of $-0,001045$ is the regression coefficient for temperature. The predicted value for each observation is the intercept $(-11,531632)$ plus the regression coefficient times its value of each independent variables. 
Table 4. The regression statistics.

\begin{tabular}{lrr}
\hline & Coefficients & Standard Error \\
\hline Intercept & $-11,531632$ & 0,4386 \\
Temp. & $-0,001045$ & 0,0002 \\
$\mathrm{X}$ & $-0,000131$ & 0,0003 \\
$\mathrm{Y}$ & 0,000419 & 0,0004 \\
$\mathrm{Z}$ & $-0,000402$ & 0,0003 \\
Power & 0,005671 & 0,0002 \\
\hline
\end{tabular}

Therefor the multiple linear regression is as follows:

$R(t)=(-0,001045 \times T(t))-\left(0,000131 \times X_{X}(t)\right)+\left(0,000419 \times X_{Y}(t)\right)-\left(0,000402 \times X_{Z}(t)\right)+$ $(0,005671 \times P(t))-11,531632$

The standard error of temperature is 0,0002 denoting that $95 \%$ confidence interval for temperature would be $-0,001045 \pm(1,96 \times 0,0002)$ or ranging from a low of $-0,000596$ to a high of $-0,001491$.

The temperature, vibration (acceleration in $X, Y, Z$ direction) and power data are inputted to the formula (6), then the wear on each time is plotted in the graphics as shown in Figure 4.

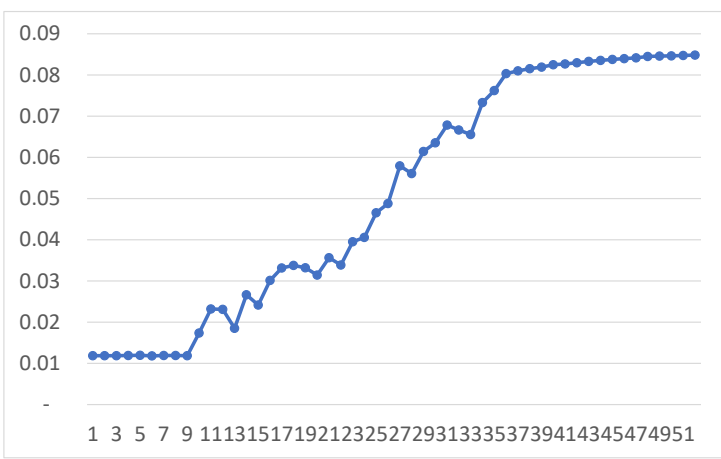

Fig. 4. The wear of cutting tool at time.

Then, the wear of cutting tool at time distribution identified using Minitab 17. Figure 5 show $\mathrm{p}$-value $<0,001$. It indicates cutting tool wear is fit into Weibull distribution with $\alpha=$ $5 \%$. This distribution has shape parameter 1,85683 and scale parameter 0,05736 . 


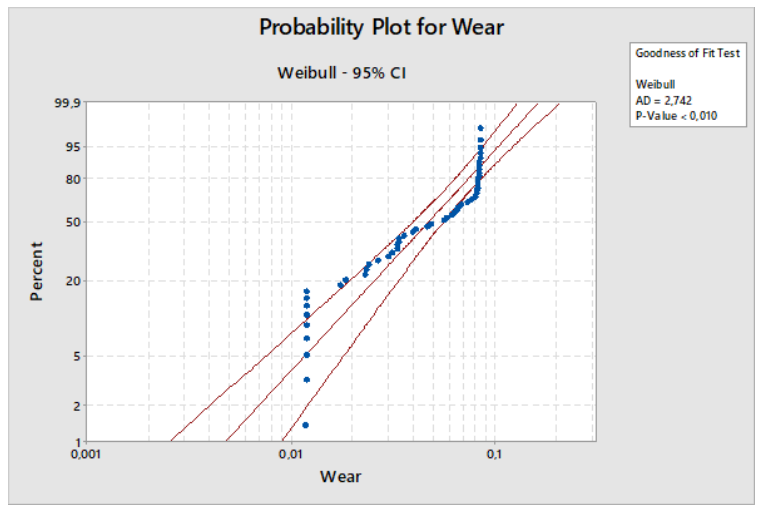

Fig. 5. Probability Plot of Wear.

Function of the cutting tool wear in Weibull distribution is as follows:

$$
R(t)=e^{-\left(\frac{t}{0,05736}\right)^{1,85683}}
$$

\section{Conclusion}

Refers to the results of analysis, implementation, and testing of cutting tool on the conventional lathe, this paper can conclude that the application manages to retrieve data from temperature sensors, vibrating sensors, and electrical sensors attached to cutting tool on lathe by the CTCMS prototype in stage one.

This research is supported and funded by Penelitian Strategis Nasional Tahun Anggaran 2018 focus on Teknologi Informasi dan Komunikasi by Kementrian Riset, Teknologi dan Pendidikan Tinggi and Kopertis Wilayah IV Jawa Barat-Banten.

\section{References}

1. C. Baur, D. Wee, Manufacturing's Next Act McKinsey Report June 2015 (2015)

2. I.P. Gania, A. Stachowiak, J. Oleskow-Szlapka, Flexible Manufacturing Systems: Industry 4.0 Solution, 24 ${ }^{\text {th }}$ International Conference on Production Research (2017)

3. A.Setiawan, R.Wangsaputra, Y.Y.Martawirya, A.H. Halim, Applied Mechanics and Material, 842, 345-354 (2016)

4. A.Setiawan, R.Wangsaputra, Y.Y.Martawirya, A.H. Halim, IOP Conf. Series: Materials Science and Engineering, 114 (2016)

5. F.J.Taylor, International Journal of Machine Tool Design Research, 2, 119-152 (1962)

6. P.Y.Chao dan Y.D. Hwang, Journal of Intelligent Manufacturing, 8, 107-115 (1996)

7. Z.Vagnorius, M.Rausand, K.Sorby, European Journal of Operational Research 206, 407-416 (2010)

8. F.Cus, U.Zuperl, Journal of Mechanical Engineering, 57, 142-150 (2011) 
9. P.Hou, M.Zhang, L.Gao, R.Li, International Journal of Applied Science and Technology, 4, 4 (2014)

10. P.Kovac, M.Gostimirovic and D.Milikic, The International Journal for Manufacturing Science \& Production, 2, 4 (1999)

11. P.Kovac, I.Mankova, M.Gostimirovic, M.Sekulic, B.Savkovic, Journal of Production Engineering, 14 (2011) 